\title{
Accumulated Dose of Intensity-Modulated Radiotherapy for Head and Neck Cancer Using Deformable Registration of Two Sets of Computed Tomography Images
}

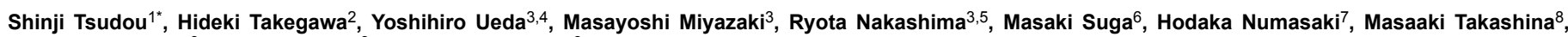
Masahiko Koizumi ${ }^{8}$, Teruki Teshima ${ }^{3}$ and Kinji Nishiyama ${ }^{9}$

${ }^{1}$ Division of Medical Technology Support, Kobe Minimally Invasive Cancer Center, 8-5-1, Minatojima, Nakamachi, Chuo-ku, Kobe-city, Hyogo, 650-0046, Japan

${ }^{2}$ Department of Radiology, Kansai Medical University, 2-5-1 Shinmachi, Hirakata-city, Osaka, 573-1010, Japan

${ }^{3}$ Department of Radiation Oncology, Osaka Medical Center for Cancer and Cardiovascular Diseases, 1-3-3 Nakamichi Higashinari-ku, Osaka-city, Osaka, 537-8511, Japan

${ }^{4}$ Department of Radiation Oncology, Graduate School of Medicine, Osaka University, 2-2 Yamadaoka, Suita-city, Osaka, 565-0871, Japan

${ }^{5}$ Department of Radiation Oncology and Image-applied Therapy, Graduate School of Medicine, Kyoto University, 54 Kawaharacho, Shogoin, Sakyo-ku, Kyoto-city, Kyoto, 606-8507, Japan

${ }^{6}$ Department of Radiation Physics, Hyogo Ion Beam Medical Center, 1-2-1 Koto, Shingucho, Tatsuno-city, Hyogo, 679-5165, Japan

${ }^{7}$ Department of Functional Diagnostic Science, Graduate School of Medicine, Osaka University, 1-7 Yamadaoka, Suita-city, Osaka, 565-0871, Japan

${ }^{8}$ Department of Medical Physics and Engineering, Graduate School of Medicine, Osaka University, 1-7 Yamadaoka, Suita-city, Osaka, 565-0871, Japan

${ }^{9}$ Department of Radiology, Yao Municipal Hospital, 1-3-1 Ryugecho, Yao-city, Osaka, 581-0069, Japan

*Corresponding author: Shinji Tsudou, Division of Medical Technology Support, Kobe Minimally Invasive Cancer Center, 8-5-1, Minatojima, Nakamachi, Chuo-ku, Kobe-city, Hyogo, 650-0046, Japan, Tel: +81-78-304-4100; Fax: +81-78-304-0041; E-mail: tsudo@k-mcc.net

Received date: Oct 17, 2015, Accepted date: Nov 10, 2015, Publication date: Nov 16, 2015

Copyright: ( 2015 Tsudou S, et al. This is an open-access article distributed under the terms of the Creative Commons Attribution License; which permits unrestricted use; distribution; and reproduction in any medium; provided the original author and source are credited.

\begin{abstract}
Purpose: The aim of this study was, using deformable image registration (DIR), to evaluate alteration of dose distribution caused by patient's anatomical structure changes during a two-phase intensity-modulated radiotherapy (IMRT).

Methods: IMRT consisted of an initial plan delivering 53 Gy to gross tumor volume (GTV) and 45 Gy to elective volumes and a boost plan delivering 16.96 Gy to GTV. The subjects were 10 patients with head and neck cancer who underwent computed tomography (CT) scans twice (first CT before treatment and second CT before boost). A sum of the initial and the boost plans for the first CT was Original total plan. Using DIR, the original boost and a modified new boost plan were recalculated on the second CT and summed with the initial plan to create total plans: DIR plan and modified DIR plan.
\end{abstract}

Results: Mean dose $\left(D_{\text {mean }}\right)$ of the ipsilateral and contralateral parotids were increased by $8.0 \%(P<0.01)$ and $6.8 \%(\mathrm{P}<0.05)$ in DIR plan compared with Original total plan. Compared with DIR plan, modified DIR plan reduced $D_{\text {mean }}$ of the ipsilateral parotid $(P<0.01)$. Dose to $95 \%$ of the volume (D95) to clinical target volume for GTV (CTV1) of DIR plan was significantly higher than that of Original total plan $(P<0.01)$ and modified DIR plan $(P<0.01)$.

Conclusions: Dose summation using DIR demonstrated that the body shrinking during IMRT significantly increased the doses of both parotids and CTV1. Modified DIR plan compensated the increases in doses of the ipsilateral parotid and CTV1.

Keywords: Head and neck cancer; Two-phase intensity-modulated radiotherapy; Anatomic change; Deformable image registration; Replan

\section{Introduction}

The attainment of highly conformal dose distribution to targets, while sparing organs at risk (OARs), by intensity-modulated radiotherapy (IMRT) for head and neck cancers (HNC) has recently proved to results in favorable tumor control [1-3]. For HNC patients, radiotherapy inevitably causes weight loss due to reduced dietary intake [4] and the resultant body shrinkage alters dose distribution. In addition, tumor regression and parotid shrinkage during a radiation course reportedly affect dose distribution [5-13]. For conventional radiation therapy, the changes are generally not critical because of the simplicity of dose distribution. For IMRT, on the other hand, these changes cause problems because IMRT dose distributions are highly complicated and conformal. Several studies have reported that dose distribution changes are related to critical alternations of dosimetric parameters for targets and OARs [7-13].

Recalculation based on a series of computed tomography (CT) scans acquired over treatment courses constitutes one solution for this problem. To obtain actual dose distribution of IMRT, however, it is necessary to summate dose distributions based on different CT sets, but this summation cannot be made directly because a given CT set 
Citation: Tsudou S, Takegawa H, Ueda Y, Miyazaki M, Nakashima R, et al. (2015) Accumulated Dose of Intensity-Modulated Radiotherapy for Head and Neck Cancer Using Deformable Registration of Two Sets of Computed Tomography Images. J Nucl Med Radiat Ther 6: 264. doi:10.4172/2155-9619.1000264

Page 2 of 7

does not necessarily contain a voxel corresponding to a specific anatomical structure on another CT set. Deformable image registration (DIR) is a method for corresponding the voxel of specific anatomical point on two different CT sets [14,15].

Several studies have compared original dose distributions calculated on single simulation CT with cumulative dose distributions on several simulation CTs using DIR [9-13]. Most of these studies concerned simultaneous integrated boost (SIB) IMRT and demonstrated significant differences between original and cumulative dose distribution. The method used for IMRT at Osaka Medical Center for Cancer and Cardiovascular Diseases is not SIB but a two-phase method in which the initial plan targets both of the gross tumor volume (GTV) and elective volumes and the subsequent boost plan targets GTV exclusively. These two plans are also different in beam directions. These two plans are practically calculated for the first simulation CT (first CT). Compared with the single phase SIB, however, because the two-phase IMRT has these different aspects, the body shrinkage during IMRT could have different influence on dose distributions. To the best of our knowledge, however, no studies on the influence in the two-phase IMRT have been reported. Therefore, in our study, we acquired another simulation CT during the treatment period (second CT) and summated doses of the initial and boost plan using DIR to evaluate the effects of changes in anatomical structures on the dose distribution.

\section{Materials and Methods}

\section{Patients}

Our study involved 10 patients with HNC who underwent IMRT at Osaka Medical Center for Cancer and Cardiovascular Diseases between July 2011 and September 2012 and was approved by the institutional review board. Written informed consent was obtained from all of the subjects. Table 1 shows patient characteristics.

\begin{tabular}{|c|c|}
\hline Characteristics & No. of patients $(n=10)$ \\
\hline Gender, male/female & $10 / 0$ \\
\hline \multicolumn{2}{|l|}{ Tumor location } \\
\hline Nasopharynx & 6 \\
\hline Oropharynx & 4 \\
\hline \multicolumn{2}{|l|}{ Histology } \\
\hline Squamous cell carcinoma & 10 \\
\hline \multicolumn{2}{|l|}{ Stage } \\
\hline \multicolumn{2}{|l|}{ T stage (UICC) } \\
\hline T1 & 2 \\
\hline T2 & 5 \\
\hline T3 & 0 \\
\hline T4 & 3 \\
\hline \multicolumn{2}{|l|}{ N stage (UICC) } \\
\hline NO & 1 \\
\hline N1 & 2 \\
\hline
\end{tabular}

\begin{tabular}{|l|l|}
\hline N2 & 7 \\
\hline M stage (UICC) & 9 \\
\hline M0 & 1 \\
\hline M1 & \multicolumn{2}{|l|}{} \\
\hline Abbreviations: UICC: Union Internationale Contre le Cancer. \\
\hline
\end{tabular}

Table 1: Patient characteristics.

\section{Simulation and treatment planning}

\section{Treatment planning for first CT}

A thermoplastic face mask (CIVCO Medical Solutions, Orange City, IO) was used for patient immobilization during CT simulation and throughout the treatment. The first $\mathrm{CT}$ of the head and neck region by GE LightSpeed16 (General Electric Co, Waukesha, WI) was used for all the patients prior IMRT. The CT slice measured $512 \times 512$ pixels with pixel spacing of $0.977 \times 0.977 \mathrm{~mm}^{2}$ and slice thickness of $2.5 \mathrm{~mm}$. For the simulation $\mathrm{CT}$, points indicating the isocenter were marked on the face mask and simulation CT images were transferred to the Eclipse radiation therapy planning system (ver. 8.9.15; Varian Medical Systems, Palo Alto, CA). Target volumes and OARs were manually contoured by radiation oncologists. In accordance with the recommendations made in reports 50 and 62 by the International Commission on Radiation Units and Measurements [16,17], the primary tumor was included in GTV, which also involved lymph nodes with an axial diameter of at least $10 \mathrm{~mm}$ or more. The clinical target volume (CTV) included GTV and surrounding high-risk subclinical disease regions (CTV1) and low-risk subclinical disease regions (CTV2). The planning target volumes (PTV1 and PTV2) were set by adding isotropic $5 \mathrm{~mm}$ margins to CTV1 and CTV2, respectively. The spinal cord, brain stem, bilateral parotid glands, oral cavity, mandible, larynx, inferior pharyngeal constrictor, lens, eyes, optic nerves, and chiasm were manually contoured as OARs. Additional safety margins of $5 \mathrm{~mm}$ for the spinal cord and $1 \mathrm{~mm}$ for the brain stem were used for appropriate planning risk volumes. Intensity-modulated radiotherapy was planned to be delivered with the sliding window method using a 6 MV photon beam of the Varian 23EX linear accelerator equipped with the Millennium 120 multi-leaf collimator (Varian Medical Systems, Palo Alto, CA). For the dose calculation algorithm Analytic Anisotropic Algorithm was used. The radiation treatment consisted of two IMRT plans: 1) an initial plan delivering 53 Gy for PTV1 and 45 Gy for PTV2 concurrently in 25 fractions and 2) a boost plan of 16.96 Gy in 8 fractions exclusively for PTV1 (Table 2). The prescribed doses of the initial and boost plans were normalized to dose to $95 \%$ of the volume $\left(\mathrm{D}_{95}\right)$ of PTV1.

\begin{tabular}{|l|l|l|l|}
\hline \multicolumn{2}{|l|}{} & Dose (Gy) & Dose (Gy) \\
\hline & Fraction & PTV1 & PTV2 \\
\hline Initial plan & 25 & 53 & 45 \\
\hline Boost plan & 8 & 16.96 & - \\
\hline Total & 33 & 69.96 & 45 \\
\hline
\end{tabular}

Table 2: Dose allocation for treatment course. Abbreviations: PTV: Planning Target Volume. 
Citation: Tsudou S, Takegawa H, Ueda Y, Miyazaki M, Nakashima R, et al. (2015) Accumulated Dose of Intensity-Modulated Radiotherapy for Head and Neck Cancer Using Deformable Registration of Two Sets of Computed Tomography Images. J Nucl Med Radiat Ther 6: 264. doi:10.4172/2155-9619.1000264

Page 3 of 7

First, two IMRT plans were created for the first CT (original initial and original boost plan). The original initial and boost plans were then summed (Original total plan) and OAR doses were assessed based on the RTOG 0615 protocol [18]. The OAR constraints on dose-volume histogram (DVHs) were a maximum dose $\left(\mathrm{D}_{\max }\right)$ of less than $45 \mathrm{~Gy}$ for the spinal cord, $D_{\max }$ of less than $54 \mathrm{~Gy}$ for the brain stem and a mean dose $\left(D_{\text {mean }}\right)$ of less than 26 Gy for at least one parotid gland. The beam arrangement of the initial plan consisted of seven coplanar beams, typical gantry angles of $50^{\circ}, 70^{\circ}, 150^{\circ}, 180^{\circ}, 210^{\circ}, 290^{\circ}$ and $310^{\circ}$ were used and the boost plan beams were arranged so as to spare the bilateral parotid glands.

\section{Boost plan modification for second CT}

The second CT scan with lead balls positioned at the isocenter marks on the face mask was performed around four weeks after the start of treatment. The second CT was registered to the first CT by means of bony anatomy. Organs at risk were newly contoured manually and target volumes for the first CT were copied onto the second CT. To reflect the effect of body changes on dose distribution of the initial plan, the original initial plan was copied onto the second CT and recalculated for the latter half of the initial plan (12 sessions) (recalculated initial plan). Similarly, the original boost plan was recalculated for the second CT (recalculated boost plan). Moreover, for the second $\mathrm{CT}$, the original boost plan was modified mainly to improve the dose volume parameters of the bilateral parotids (modified boost plan).

\section{Calculation of total plan dose based on DIR}

Figure 1 shows an overview of the summative dose method using DIR, which was implemented in $\mathrm{C}++$ based on the medical image processing library Insight Segmentation and Registration Toolkit [19]. For the second CT, two registration steps were performed. The first consisted of an affine transformation-based rigid registration performed to remove the setup error between the first CT and second CT. The second registration step was a B-spline-based DIR. This DIR algorithm calculates displacement vector fields (DVFs) corresponding to the anatomic modifications occurring between the first $\mathrm{CT}$ and the second CT. The DVFs were used to deform and map the recalculated initial, recalculated boost and modified boost plans of the second CT to create the corresponding deformed plans. On the first CT, these deformed plans were summed up with the original initial plan for 13 sessions to create the total plans, that is, DIR and modified DIR plans (Table 3).

\begin{tabular}{|l|l|l|}
\hline & Initial plan & Boost plan \\
\hline Original total plan & Original initial plan for 25 sessions & Original boost plan \\
\hline DIR plan & $\begin{array}{l}\text { Original initial plan } \\
\text { for 13 sessions }+ \text { Deformed } \\
\text { recalculated } \\
\text { initial plan for 12 sessions }\end{array}$ & $\begin{array}{l}\text { Deformed } \\
\text { recalculated } \\
\text { boost plan }\end{array}$ \\
\hline $\begin{array}{l}\text { Modified DIR } \\
\text { plan }\end{array}$ & $\begin{array}{l}\text { Original initial plan } \\
\text { for 13 sessions }+ \text { Deformed } \\
\text { recalculated } \\
\text { initial plan for 12 sessions }\end{array}$ & $\begin{array}{l}\text { Deformed modified } \\
\text { boost plan }\end{array}$ \\
\hline
\end{tabular}

Abbreviations: DIR: deformable image registration.

Table 3: Planning terms used in this study.

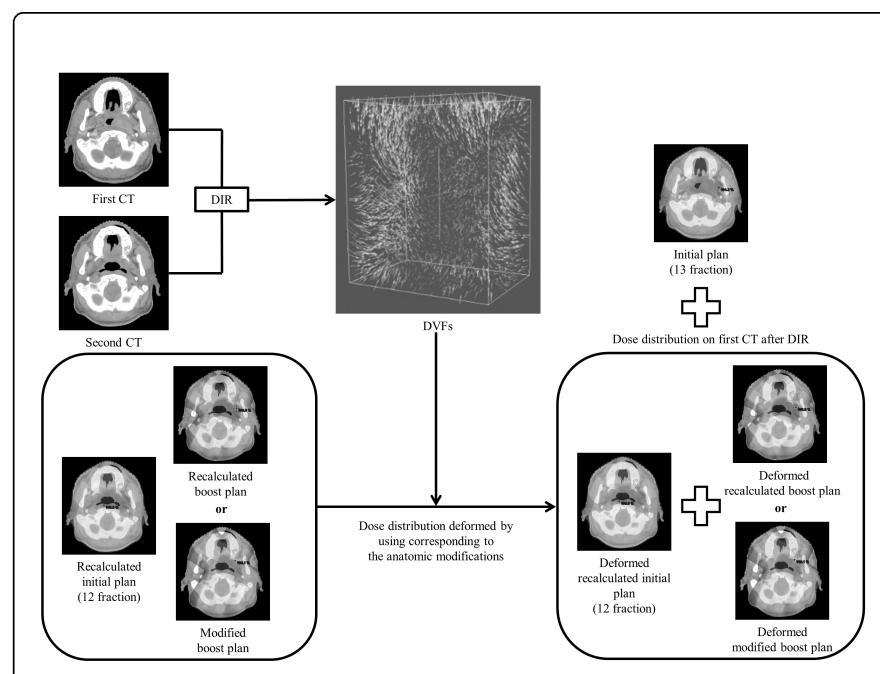

Figure 1: Overview of dose summation with DIR (DVFs displayed with Paraview). Abbreviations: CT: Computed Tomography; DIR: Deformable Image Registration; DVFs: Displacement Vector Fields.

\section{Dosimetric comparison}

Original total plan was compared with DIR plan to assess the effect of anatomical changes on dose distribution during treatment. In addition, modified DIR plan was compared with DIR plan to evaluate modification of the boost plan. The dosimetric parameters assessed were $D_{95}$ to CTV1, dose to the maximum of $2 \%$ of the volume $\left(D_{2}\right)$ of the spinal cord and brain stem, and $\mathrm{D}_{\text {mean }}$ to the parotid glands. Beam depth of the original and the recalculated boost plans was compared for quantitative evaluation of changes in body contour during treatment. These comparisons were statistically estimated with the paired t-test. A P value $<0.05$ was considered significant.

\section{Results}

Figure 2 shows the dosimetric parameters of Original total plan, DIR plan, and modified DIR plan. Dose to the maximum of $2 \%$ of the volume to the spinal cord of Original total plan, DIR plan, and modified DIR plan were $42.6 \pm 2.1 \mathrm{~Gy}, 43.0 \pm 2.1 \mathrm{~Gy}$, and $42.7 \pm 2.0 \mathrm{~Gy}$ (mean $\pm \mathrm{SD}$ ), respectively, thus showing no significant differences, nor did D2 to the brain stem $(47.0 \pm 6.1 \mathrm{~Gy}, 46.8 \pm 6.4 \mathrm{~Gy}$, and $46.8 \pm 6.1$ Gy, respectively).

Mean dose to the ipsilateral parotid of the three plans were $40.0 \pm$ $9.2 \mathrm{~Gy}, 43.2 \pm 9.2 \mathrm{~Gy}$, and $42.6 \pm 9.1 \mathrm{~Gy}$ (mean $\pm \mathrm{SD}$ ), respectively, showing a significant increase by $8.0 \%$ in $\mathrm{D}_{\text {mean }}$ of DIR plan compared to that of Original total plan $(\mathrm{P}<0.01)$, while the difference was slight but significant between the DIR and modified DIR plans $(\mathrm{P}<0.01)$. Mean dose to the contralateral parotid of the three plans were $26.4 \pm$ $7.3 \mathrm{~Gy}, 28.2 \pm 7.2 \mathrm{~Gy}$, and $27.8 \pm 7.1 \mathrm{~Gy}$ (mean $\pm \mathrm{SD}$ ), respectively, showing a significant increase by $6.8 \%$ in the Dmean of DIR plan compared to Original total plan $(\mathrm{P}<0.05)$, while the difference was not significant between DIR and modified DIR plans $(\mathrm{P}=0.07)$.

Dose to $95 \%$ of the volume to CTV1 of the three plans were $73.2 \pm$ $0.6 \mathrm{~Gy}, 73.7 \pm 0.8 \mathrm{~Gy}$, and $73.5 \pm 0.7 \mathrm{~Gy}$ (mean $\pm \mathrm{SD})$, respectively, with a slight but significant increase in D95 of DIR plan over Original total plan $(\mathrm{P}<0.01)$ and modified DIR plan $(\mathrm{P}<0.01)$. Total depth of all 
Citation: Tsudou S, Takegawa H, Ueda Y, Miyazaki M, Nakashima R, et al. (2015) Accumulated Dose of Intensity-Modulated Radiotherapy for Head and Neck Cancer Using Deformable Registration of Two Sets of Computed Tomography Images. J Nucl Med Radiat Ther 6: 264. doi:10.4172/2155-9619.1000264

Page 4 of 7

beams was $77.1 \pm 14.1 \mathrm{~mm}$ (mean $\pm \mathrm{SD}$ ) for the original boost plan for the first CT and $75.0 \pm 14.1 \mathrm{~mm}$ for the recalculated boost plan for the second CT, with a significant difference between the two plans $(\mathrm{P}<0.01)$

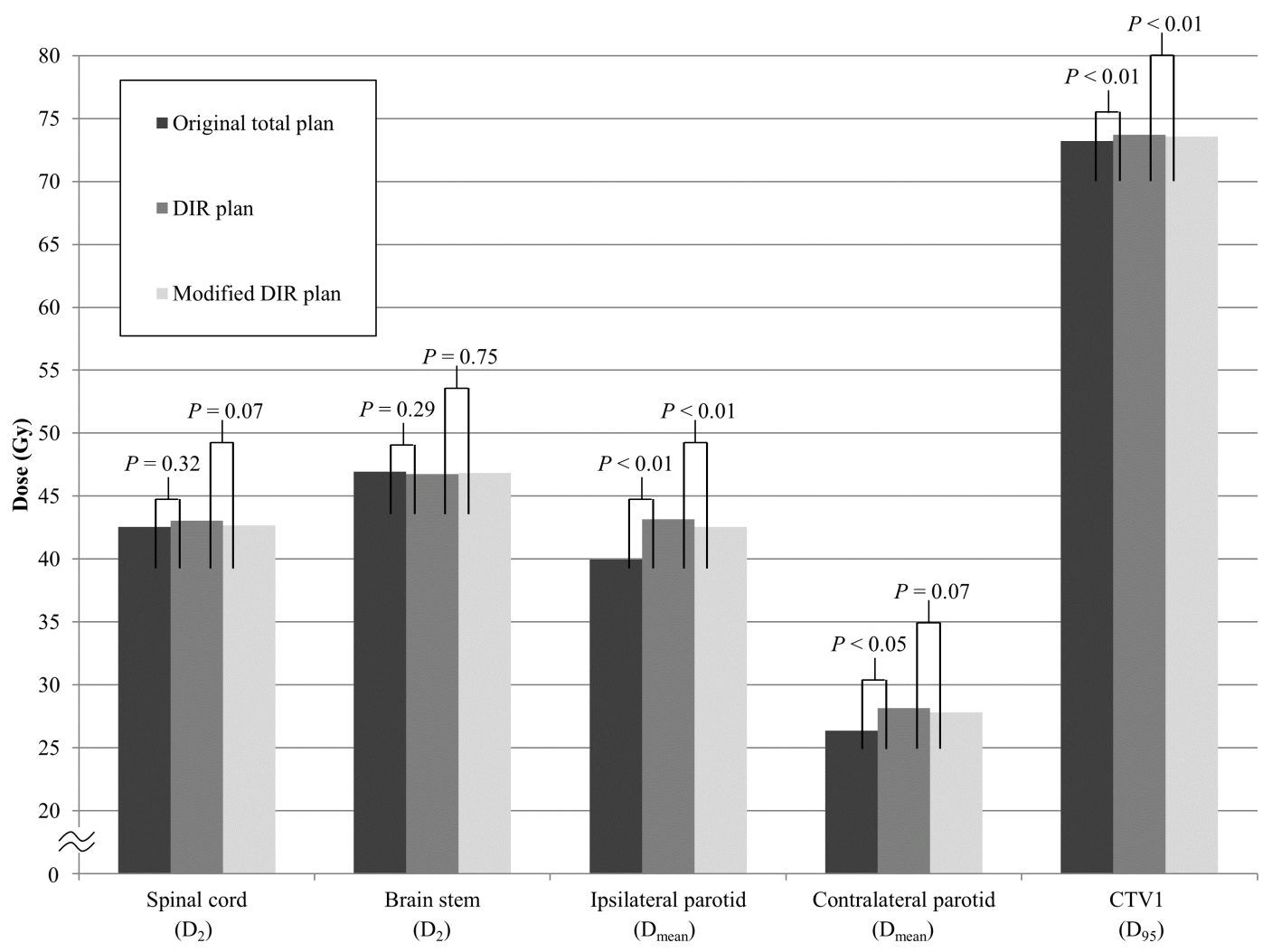

Figure 2: Comparison of dosimetric parameters between Original total plan, DIR plan, and modified DIR plan. Abbreviations: $\mathrm{D}_{2}:$ dose to the maximum $2 \%$ of the volume, a representation of maximum dose; $\mathrm{D}_{\text {mean }}$ : mean dose; CTV: Clinical Target Volume; $\mathrm{D}_{95}$ : dose to the $95 \%$ of the volume.

\section{Discussion}

Several studies of cumulative dosimetric parameters for DIR of repeated CTs during an IMRT course have analyzed the usefulness of DIR for evaluation of alterations in dose volume parameters due to changes in body contours and organ shifts during SIB IMRT. Most of these studies assessed the volumes to the spinal cord, brain stem, parotid glands, and CTV. Table 4 shows a comparison between the doses for Original total plan and DIR plan analyzed in our and previous studies.

\begin{tabular}{|l|l|l|l|l|l|l|l|}
\hline Author & No. of & CT during IMRT & IMRT technique & Results & \multicolumn{3}{|l|}{} \\
\cline { 4 - 7 } & Patients & & & Spinal cord $\left(\mathbf{D}_{2}\right)$ & Brain stem $\left(\mathbf{D}_{2}\right)$ & Parotid $\left(\mathbf{D}_{\text {mean }}\right)$ & CTV $\left(\mathbf{D}_{95}\right)$ \\
\hline Lee et al. [9] & 10 & Daily & Not stated & Not stated & Not stated & $\begin{array}{l}\text { Increase in DIR plan } \\
\text { by 3 Gy }\end{array}$ & Not stated \\
\hline $\begin{array}{l}\text { O' Daniel et al. } \\
{[10]}\end{array}$ & 11 & Twice per week & SIB & Not significant & Not stated & $\begin{array}{l}\text { Ipsilateral: } \\
\text { Increase in DIR plan } \\
\text { by 3 Gy } \\
(P=0.026) \\
\text { Contralateral: }\end{array}$ & Not significant \\
\hline
\end{tabular}


Citation: Tsudou S, Takegawa H, Ueda Y, Miyazaki M, Nakashima R, et al. (2015) Accumulated Dose of Intensity-Modulated Radiotherapy for Head and Neck Cancer Using Deformable Registration of Two Sets of Computed Tomography Images. J Nucl Med Radiat Ther 6: 264. doi:10.4172/2155-9619.1000264

Page 5 of 7

\begin{tabular}{|c|c|c|c|c|c|c|c|}
\hline & & & & & & $\begin{array}{l}\text { Increase in DIR plan } \\
\text { by } 1 \mathrm{~Gy} \\
(\mathrm{P}=0.016)\end{array}$ & \\
\hline Wu et al. [11] & 11 & Six times weekly & SIB & *Not significant & "Not significant & Significant increased & Not significant \\
\hline Xivry et al. [12] & 10 & Four times & SIB & $\begin{array}{l}\text { Increase in DIR plan } \\
\text { by } 0.78 \mathrm{~Gy}\end{array}$ & Not stated & $\begin{array}{l}\text { Ipsilateral: } \\
\text { Increase in DIR plan } \\
\text { by } 0.93 \mathrm{~Gy} \\
\text { Contralateral: } \\
\text { Increase in DIR plan } \\
\text { by } 0.53 \mathrm{~Gy}\end{array}$ & $\begin{array}{l}\text { Increase in DIR plan } \\
\text { by } 0.06 \mathrm{~Gy}\end{array}$ \\
\hline $\begin{array}{l}\text { Castadot et al. } \\
\text { [13] }\end{array}$ & 10 & Four times & Not stated & Difference 0.9 Gy & Not stated & $\begin{array}{l}\text { Increase in DIR plan } \\
\text { by } 0.8 \mathrm{~Gy}\end{array}$ & Not significant \\
\hline Our study & 10 & Once & Two-step & $\begin{array}{l}\text { Not significant } \\
(P=0.32)\end{array}$ & $\begin{array}{l}\text { Not significant } \\
(P=0.29)\end{array}$ & $\begin{array}{l}\text { Ipsilateral: } \\
\text { Increase in DIR plan } \\
\text { by } 3.2 \mathrm{~Gy} \\
(\mathrm{P}<0.01) \\
\text { Contralateral: } \\
\text { Increase in DIR plan } \\
\text { by } 1.8 \mathrm{~Gy} \\
(\mathrm{P}<0.05)\end{array}$ & $\begin{array}{l}\text { Increase in DIR plan } \\
\text { by } 0.5 \mathrm{~Gy} \\
(P<0.01)\end{array}$ \\
\hline
\end{tabular}

"Wu et al. used dose to the maximum $1 \%$ of the volume of the spinal cord and brain stem. Abbreviations: CT: Computed Tomography; IMRT: Intensity-Modulated Radiotherapy; $D_{2}$ : dose to the maximum $2 \%$ of the volume, a representation of maximum dose; $D_{\text {mean }}$ : mean dose; CTV: clinical target volume; $D_{95}$ : dose to the $95 \%$ of the volume; DIR: Deformable Image Registration; SIB: Simultaneous Integrated Boost

Table 4: Comparison of the original total plan and DIR plan.

In our study of two-phase IMRT, we could find no differences in $\mathrm{D}_{2}$ to the spinal cord and brain stem between Original total plan, DIR plan and modified DIR plan. Wu et al. [11] acquired a CT scan every week during an IMRT course for HNC, recalculated the SIB plan for every CT scan and compared the initial plan dosimetric parameters for the first CT with cumulative doses after DIR. Doses to the spinal cord and brain stem were found to be markedly stable. Other studies $[10,12,13]$ reported similar results for comparisons between the initial and cumulative doses to the spinal cord and brain stem. The spinal cord and brain stem are located in the middle of the body and therefore do not shift after body weight loss and/or tumor shrinkage, which is reportedly the reason for the similarity of the doses.

O’Daniel et al. [10] acquired CT scans twice a week during SIB IMRT for HNC, applied the initial plan to the repeated CTs, and produced an integrated plan by using DIR. The median $\mathrm{D}_{\text {mean }}$ to the ipsilateral and contralateral parotids was higher for the integrated plan than for the original plan by $3.0 \mathrm{~Gy}(\mathrm{P}<0.026)$ and $1.0 \mathrm{~Gy}(\mathrm{P}<0.016)$, respectively. They stated that this dose increase was caused not only by setup uncertainty but also by dramatic anatomical changes that occurred over the course of radiotherapy as the patients lost weight, their tumor volume and parotid gland volume shrank, with the center of the parotid gland volume moving medially into the high-dose region. Most other reports [9,11-13] reported that cumulative doses were significantly higher than the dose for the original plan. Our study found that the dose to the parotids for DIR plan was higher than for Original total plan by $8.0 \%$ for the ipsilateral and $6.8 \%$ for the contralateral parotid. Thus, the results for DIR plans demonstrated that the $\mathrm{D}_{\text {mean }}$ to the parotids of Original total plan was significantly underestimated, especially to the ipsilateral parotid. We speculate that the primary reason for the dose elevation is the medial shift of the parotids to the higher dose target, and since the ipsilateral parotid is closer to the higher dose region than the contralateral parotid, this would explain why the elevation is more prominent for the ipsilateral parotid.

Xivry et al. [12] acquired CT images 5 times during an IMRT course for HNC and recalculated the SIB plan for each CT set, and cumulated doses for DIR. The therapeutic $\mathrm{D}_{95}$ dose to CTV was $68.43 \mathrm{~Gy}$ for the actual cumulative dose and 68.37 Gy for the dose of the initial plan. Their study and most other studies $[10,11,13]$ found only minor and insignificant differences in target doses between the actual cumulative doses and those of the original plan. These studies referred to changes in body contour during IMRT, but did not quantitatively assess such changes. The difference in CTV1 $\mathrm{D}_{95}$ between DIR plan and Original total plan observed in our study was small and clinically not critical but statistically significant. We measured the beam depth of the original boost plan for the first $\mathrm{CT}$ and the recalculated boost plan for the second CT and proved that the total beam depth for the recalculated boost plan significantly decreased probably due to body shrinking. This reduction in depth is thought to be the reason for the higher CTV1 $\mathrm{D}_{95}$ of DIR plan.

Table 5 shows a comparison of dose parameters between DIR plan and modified DIR plan of a previous study and our study. Castadot et al. [13] replanned during IMRT, evaluated its effects and found that replanning did not reduce $\mathrm{D}_{\text {mean }}$ to the parotids. Wu et al. [11] demonstrated that replanning mid-course during SIB-IMRT for HNC efficiently reduced $D_{\text {mean }}$ to the parotids by 3 to $6 \%$. Thus, the effect of replanning on parotid dose reduction has been controversial. Neither Castadot et al. [13] nor $\mathrm{Wu}$ et al. [11] assessed ipsilateral and contralateral parotid doses separately, our study, on the other hand, 
Citation: Tsudou S, Takegawa H, Ueda Y, Miyazaki M, Nakashima R, et al. (2015) Accumulated Dose of Intensity-Modulated Radiotherapy for Head and Neck Cancer Using Deformable Registration of Two Sets of Computed Tomography Images. J Nucl Med Radiat Ther 6: 264. doi: $10.4172 / 2155-9619.1000264$

Page 6 of 7

assesses the doses separately and found that, while the contralateral parotid $\mathrm{D}_{\text {mean }}$ of DIR and modified DIR plans did not differ, the ipsilateral parotid $\mathrm{D}_{\text {mean }}$ of modified DIR plan was significantly lower than that of DIR plan. Because the ipsilateral parotid may have been closer than the contralateral parotid to the primary tumor and metastatic lymph nodes that were present in the higher dose region and thus shrank during IMRT, the medial shift of the ipsilateral parotid resulted in a more marked elevation of its dose. Modified DIR plan, which compensates for the medial shift, is therefore assumed to be more effective for the ipsilateral parotid.

\begin{tabular}{|c|c|c|c|c|}
\hline \multirow[t]{2}{*}{ Author } & \multicolumn{4}{|l|}{ Results } \\
\hline & Spinal cord $\left(D_{2}\right)$ & Brain stem $\left(D_{2}\right)$ & Parotid ( $\left.\mathrm{D}_{\text {mean }}\right)$ & CTV $\left(D_{95}\right)$ \\
\hline Castadot et al. [13] & $\begin{array}{l}\text { Decrease in modified } \\
\text { DIR plan by } 1.9 \text { Gy }\end{array}$ & Not stated & Not significant & $\begin{array}{l}\text { Decrease in modified } \\
\text { DIR plan by } 3.1 \mathrm{~Gy} \\
\text { (target volume modified) }\end{array}$ \\
\hline Wu et al. [11] & “Not significant & "Not significant & $\begin{array}{l}\text { Decrease in modified } \\
\text { DIR plan by 3-6\% }\end{array}$ & Not significant \\
\hline Our study & $\begin{array}{l}\text { Not significant } \\
(P=0.07)\end{array}$ & $\begin{array}{l}\text { Not significant } \\
(P=0.75)\end{array}$ & $\begin{array}{l}\text { Ipsilateral: } \\
\text { decrease in modified DIR plan by } 1.9 \text { Gy } \\
(P<0.01) \\
\text { Contralateral: } \\
\text { Not significant }(P=0.07)\end{array}$ & $\begin{array}{l}\text { Decrease in modified } \\
\text { DIR plan by } 0.2 \mathrm{~Gy} \\
(\mathrm{P}<0.01)\end{array}$ \\
\hline
\end{tabular}

"Wu et al. used dose to the maximum $1 \%$ of the volume of the spinal cord and brain stem. Abbreviations: DIR: Deformable Image Registration; $D_{2}$ : dose to the maximum $2 \%$ of the volume, a representation of maximum dose; $D_{\text {mean }}$ : mean dose; CTV: Clinical Target Volume; $D_{95}$ : dose to the $95 \%$ of the volume.

Table 5: Comparison of DIR plan and modified DIR plan.

In some DIR studies assessing changes in IMRT dose distribution caused by body shrinking, CT scans were acquired repeatedly throughout an IMRT course. A limitation of our study was that we acquired the second CT only once midway through the IMRT course. Hence, anatomical changes after the second CT could not be considered and the differences in dosimetric parameters were relatively small and clinically less significant than those in other studies.

In conclusion, our study for two-phase IMRT clarified that body shrinking during IMRT induced increases in the doses to both parotids and CTV1. New boost plans in our study could compensate the increases in doses of the ipsilateral parotid and CTV1.

\section{Funding}

This work was supported by the Japan Society for the Promotion of Science (JSPS) Core-to-Core Program [No. 23003].

\section{Acknowledgements}

This work was supported by all staff at Department of Radiation Oncology, Osaka Medical Center for Cancer and Cardiovascular Diseases.

\section{Conflicts of Interest}

There are no conflicts of interest.

\section{References}

1. Puri DR, Chou W, Lee N (2005) Intensity-modulated radiation therapy in head and neck cancers: dosimetric advantages and update of clinical results. Am J Clin Oncol 28: 415-423.
2. Grégoire V, De Neve W, Eisbruch A, Lee N, Van den Weyngaert D, et al. (2007) Intensity-modulated radiation therapy for head and neck carcinoma. Oncologist 12: 555-564.

3. Chao KS, Low DA, Perez CA, Purdy JA (2000) Intensity-modulated radiation therapy in head and neck cancers: The Mallinckrodt experience. Int J Cancer 90: 92-103.

4. Chencharick JD, Mossman KL (1983) Nutritional consequences of the radiotherapy of head and neck cancer. Cancer 51: 811-815.

5. Hansen EK, Bucci MK, Quivey JM, Weinberg V, Xia P (2006) Repeat CT imaging and replanning during the course of IMRT for head-and-neck cancer. Int J Radiat Oncol Biol Phys 64: 355-362.

6. Han C, Chen YJ, Liu A, Schultheiss TE, Wong JY (2008) Actual dose variation of parotid glands and spinal cord for nasopharyngeal cancer patients during radiotherapy. Int J Radiat Oncol Biol Phys 70: 1256-1262.

7. Barker JL Jr, Garden AS, Ang KK, O'Daniel JC, Wang H, et al. (2004) Quantification of volumetric and geometric changes occurring during fractionated radiotherapy for head-and-neck cancer using an integrated CT/linear accelerator system. Int J Radiat Oncol Biol Phys 59: 960-970.

8. Robar JL, Day A, Clancey J, Kelly R, Yewondwossen M, et al. (2007) Spatial and dosimetric variability of organs at risk in head-and-neck intensity-modulated radiotherapy. Int J Radiat Oncol Biol Phys 68: 1121-1130.

9. Lee C, Langen KM, Lu W, Haimerl J, Schnarr E, et al. (2008) Assessment of parotid gland dose changes during head and neck cancer radiotherapy using daily megavoltage computed tomography and deformable image registration. Int J Radiat Oncol Biol Phys 71: 1563-1571.

10. O'Daniel JC, Garden AS, Schwartz DL, Wang H, Ang KK, et al. (2007) Parotid gland dose in intensity-modulated radiotherapy for head and neck cancer: is what you plan what you get? Int J Radiat Oncol Biol Phys 69: 1290-1296.

11. Wu Q, Chi Y, Chen PY, Krauss DJ, Yan D, et al. (2009) Adaptive replanning strategies accounting for shrinkage in head and neck IMRT. Int J Radiat Oncol Biol Phys 75: 924-932.

12. Orban de Xivry J, Castadot P, Janssens G, Lee JA, Geets X, et al. (2010) Evaluation of the radiobiological impact of anatomic modifications 
Citation: Tsudou S, Takegawa H, Ueda Y, Miyazaki M, Nakashima R, et al. (2015) Accumulated Dose of Intensity-Modulated Radiotherapy for Head and Neck Cancer Using Deformable Registration of Two Sets of Computed Tomography Images. J Nucl Med Radiat Ther 6: 264. doi:10.4172/2155-9619.1000264

Page 7 of 7

during radiation therapy for head and neck cancer: can we simply summate the dose? Radiother Oncol 96: 131-138.

13. Castadot P, Lee JA, Geets X, Grégoire V (2010) Adaptive radiotherapy of head and neck cancer. Semin Radiat Oncol 20: 84-93.

14. Crum WR, Hartkens T, Hill DL (2004) Non-rigid image registration: theory and practice. Br J Radiol 77 Spec No 2: S140-153.

15. Brock KK (2007) Image registration in intensity-modulated, imageguided and stereotactic body radiation therapy. Front Radiat Ther Oncol 40: 94-115.

16. International Commission on Radiation Units and Measurements (ICRU) (1993) ICRU Report No. 50: Prescribing, recording, and reporting photon beam therapy. Bethesda, MD.
17. International Commission on Radiation Units and Measurements (ICRU) (1999) ICRU Report No. 62: Prescribing, recording, and reporting photon beam therapy (supplement to ICRU report 50). Bethesda, MD.

18. https://www.rtog.org/ClinicalTrials/ProtocolTable/StudyDetails.aspx? study $=0615$.

19. Ibanez L, Schroeder W, Ng L (2005) The ITK software guide. Kitware Inc, New York. 